\title{
Use of in-house PCR for identification of Mycobacterium tuberculosis in BACTEC broth cultures of respiratory specimens
}

\author{
Ana Cláudia Carvalho Gouveia/ ${ }^{+}$, Kathleen D. Eisenach', Solange Alves Vinhas, \\ Fabiola Karla Corrêa Ribeiro, Renata Lyrio Peres, Reynaldo Dietze, David Jamil Hadad, Moisés Palaci
}

Núcleo de Doenças Infecciosas, Centro de Ciências da Saúde, Universidade Federal do Espírito Santo, Av. Marechal Campos 1468, Maruipe, 29040-091 Vitória, ES, Brasil 'Departments of Pathology and Microbiology and Immunology, University of Arkansas for Medical Sciences, Little Rock, Arkansas, USA

We evaluated the ability of a PCR assay to identify Mycobacterium tuberculosis complex (MTBC) from positive $B A C T E C^{\circledR} 12 B$ broth cultures. A total of 107 sputum samples were processed and inoculated into Ogawa slants and $B A C T E C^{\circledR} 12 B$ vials. At a growth index $(G I) \geq 30,1.0 \mathrm{ml}$ of the $12 \mathrm{~B}$ broth was removed, stored, and assayed with $P C R$. Molecular results were compared to those obtained by phenotypic identification methods, including the BACTEC ${ }^{\circledR}$ NAP method. The average times required to perform PCR and NAP were compared. Of the 107 broth cultures evaluated, 90 were NAP positive, while 91 were PCR positive for MTBC. Of particular interest were three contaminated $B A C T E C^{\circledR} 12 B$ broth cultures yielding microorganisms other than acid-fast bacilli growth with a MTBC that were successfully identified by $P C R$, resulting in a mean time of 14 days to identify MTBC before NAP identification. These results suggest that $P C R$ could be used as an alternative to the NAP test for the rapid identification of MTBC in BACTEC ${ }^{\circledR} 12 B$ cultures, particularly in those that contained both $\mathrm{MTBC}$ and nontuberculous mycobacteria.

Key words: Mycobacterium tuberculosis - identification - PCR - BACTEC ${ }^{\circledast} 12 \mathrm{~B}$ - culture - diagnosis

The rapid and specific detection of Mycobacterium tuberculosis in clinical samples remains difficult despite years of research. The introduction of the $\mathrm{BACTEC}^{\circledR} 460$ and, more recently, the BACTEC ${ }^{\circledR}$ MGIT 960 (Becton Dickinson Diagnostic Instruments, Sparks, USA) have made possible major improvements in mycobacterial cultures by providing more rapid detection of mycobacteria (Cruciani et al. 2004, Rishi et al. 2007). In our setting, the BACTEC ${ }^{\circledR}$ systems, in conjunction with the NAP ( $\rho$-nitro- $\alpha$-acetylamino- $\beta$-hydroxy-propiophenone), are very specific for distinguishing $M$. tuberculosis complex (MTBC) from non-tuberculous mycobacteria (NTM), but they may require approximately six days for interpretable results (Laszlo \& Siddiqi 1984, Siddiqi 1989, Giampaglia et al. 2007). DNA probes have significantly decreased the length of time required for the identification of M. tuberculosis and other mycobacterial species (Rusch-Gerdes \& Richter 2004, Spada et al. 2005). A few studies have evaluated molecular techniques, such as the Gen-Probe MTB Accuprobe (Ellner et al. 1988) and Gen-Probe Amplified Mycobacterium Tuberculosis Direct Test (Bergmann \& Woods 1999, Desmond \& Lo-

\footnotetext{
Financial support: Tuberculosis Research Unit (TBRU), Rede Brasileira de Pesquisa em Tuberculose (REDE TB), CAPES

The authors do not have a commercial or other association that might pose a conflict of interest.

+Corresponding author: ana.bioquimica@gmail.com

Received: 19 March 2008

Accepted: 20 June 2008
}

retz 2001), for their ability to identify the MTBC directly from BACTEC ${ }^{\circledR} 12 \mathrm{~B}$ broth cultures in attempts to further decrease turnaround time. These commercial tests offer several advantages over conventional biochemical identification methods for rapid detection and identification, such as turnaround time for results, reliability, reproducibility, and the possibility of improving patient management (Woods 2002). However, most of these tests have not yet provided easy access to the routine procedures performed in the clinical mycobacteriology laboratory, especially in low-income countries where tuberculosis is an important public health problem (CRPHF 2002, Dowdy et al. 2003, Kivihya-Ndugga et al. 2004, Ducati et al. 2006). In-house PCR might be attractive alternatives for these commercial molecular methods, assuming that in-house PCR is cheaper, faster, and relatively easy to perform (Cleef et al. 2005, Muhumuza et al. 2006). In this study, we aimed to determine the ability of an in-house PCR assay for earlier identification of MTBC on BACTEC ${ }^{\circledR} 12 \mathrm{~B}$ broth cultures using a pair of IS6110-derived primers. Although many laboratories have replaced the BACTEC $^{\circledR} 460$ radiometric system with non-radiometric culture systems, we assume that this in-house PCR assay can also be applied to the BACTEC $^{\circledR}$ MGIT 960 system, whichuses non-radiometric fluorescence technology.

\section{PATIENTS, MATERIALS AND METHODS}

Clinical specimens - This study included a total of 107 respiratory specimens (sputum) from 95 patients being screened or under treatment for tuberculosis at the Hospital Universitário Cassiano Antônio Moraes (Espírito Santo, Brazil) between March 2004 and March 2005. A Fisher's exact test with a 0.05 one-sided significance level was used to measure this sample size. 
Sample processing - Sputum samples were digested with dithiotreitol (DTT) to a final concentration of $0.1 \%$ for $5 \mathrm{~min}$ on a shaker, decontaminated with an equal volume of $\mathrm{N}$-acetyl-cysteine- $\mathrm{NaOH}$ to a final concentration, and mixed thoroughly for $5 \mathrm{~min}$ before being left to stand for $15 \mathrm{~min}$ at room temperature. After decontamination, phosphate buffer $(\mathrm{pH}$ 6.8) was added to all the specimens for a final volume of $50 \mathrm{ml}$ and then mixed thoroughly. The mixture was centrifuged at $4000 \mathrm{~g}$ at $4^{\circ} \mathrm{C} / 15 \mathrm{~min}$, and sediment was adjusted to $2.0 \mathrm{ml}$ with phosphate buffer (Kent \& Kubica 1985). The sediment was subjected to microscopic examination for acid-fast bacilli (AFB) by standard procedures with fluorescent stain (Collins et al. 1997).

Culture and identification - The sediment was inoculated in the culture media: $0.2 \mathrm{ml}$ onto Ogawa medium, and $0.5 \mathrm{ml}$ into BACTEC $^{\circledR} 12 \mathrm{~B}$ vials, to which $0.1 \mathrm{ml}$ of an antimicrobial supplement (PANTA ${ }^{\mathrm{TM}}$ ) had previously been added. Cultures were then incubated at $37^{\circ} \mathrm{C}$ for a maximum of six weeks. The solid media were examined weekly for visible growth, and the BACTEC ${ }^{\circledR} 12 \mathrm{~B}$ broth was analyzed by the BACTEC ${ }^{\circledR} 460$ TB instrument according to the manufacturer's instructions (Kent \& $\mathrm{Ku}$ bica 1985, Siddiqi 1989). When the GI of a bottle reached $\geq 30$, aliquots of broth were aseptically removed for (i) smears stained by the Ziehl-Neelsen (ZN) method, (ii) inoculation onto a $5 \%$ sheep blood agar plate to test the purity of broth cultures, and (iii) analysis by the PCR. The remainder was monitored daily to $\mathrm{GI} \geq 50$, at which time a BACTEC ${ }^{\circledR}$ NAP TB differentiation test was set up. All isolates were identified as MTBC according to their growth characteristics as colony morphology, resistance to thiophen-2-carboxylic acid hydrazide (Giampaglia et al. 2005), and susceptibility to NAP (Fig. 1).

$B A C T E C^{\circledR} N A P T B$ differentiation test - At $\mathrm{GI} \geq 50$, a NAP test was set up following the manufacturer's instructions in the BACTEC ${ }^{\circledR} 460$ manual. Both the control and NAP vials were monitored daily, and the results were interpreted according to the manual (Siddiqi 1989).

PCR assay - In preparation for PCR, $1.0 \mathrm{ml} \mathrm{12B}$ aliquots were heat-killed at $90^{\circ} \mathrm{C}$ for $90 \mathrm{~min}$ and concentrated by centrifuging at $13,000 \mathrm{~g}$ for $2 \mathrm{~min}$. The supernatant was discarded, and the sediment was resuspended in about $5 \mu \mathrm{l}$ of water. This was the cell sample that was used for the amplification. Aliquots from $12 \mathrm{~B}$ vials were frozen at $-20^{\circ} \mathrm{C}$ until use. Oligonucleotides of $18 \mathrm{bp}$ homologous for sequences in the insertion sequence IS6110 specific for MTBC were used as primers for PCR. The forward primer (5'GGCTGTGGGTAGCAGACC3') and reverse primer (5'CGGGTCCAGATGGCTTGC3') generated a 123 bp product of IS6110. The amplification was performed with a final volume of $25 \mu 1$ using a LCx Thermal Cycler (Abbott Diagnostic Division, Abbott Park, IL, USA). Each reaction tube contained $2 \mu \mathrm{l}$ of the heat-killed suspension, $5 \mathrm{pmol}$ of IS6110 primers, $4 \mathrm{mM} \mathrm{MgCl}, 2.5 \mu 110 \mathrm{X}$ buffer

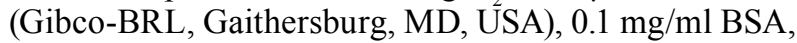
$200 \mu \mathrm{M}$ each of dATP, dGTP, dCTP, dTTP, and $1.25 \mathrm{U}$ of Taq DNA polymerase (Cenbiot, Porto Alegre, Brazil).

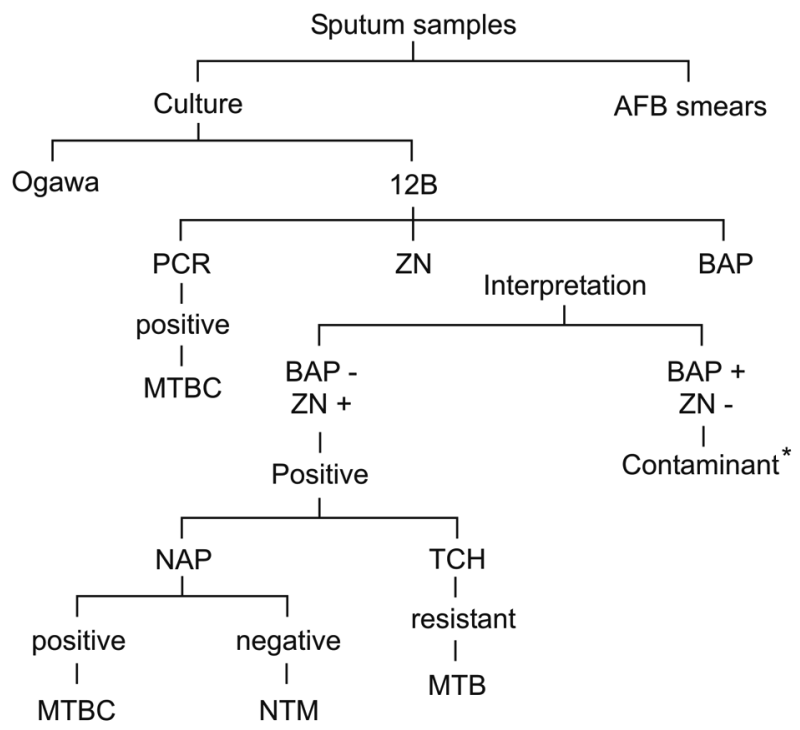

Fig. 1: algorithm for identify $M$. tuberculosis complex from BACTEC $^{\circledR} 12$ B vials. AFB: acid fast bacilli; BAP: blood agar plate; GI: growth index; MTB: M. tuberculosis; MTBC: M. tuberculosis complex; NAP: $\rho$-nitro- $\alpha$-acetylamino- $\beta$-hydroxy-propiophenone test; NTM: non-tuberculous mycobacteria; PCR: polymerase chain reaction; TCH: thiophen-2-carboxylic acid hydrazide; ZN: Ziehl Neelsen; -: negative; +: positive. Asterisk indicates mycobacterial cultures contaminated with other microorganisms; such cultures were decontaminated and retested.

Positive controls were provided by reactions containing M. tuberculosis H37Ra (ATCC 25177), and negative controls by using Escherichia coli (ATCC 29522) and sterile distilled water. The thermal cycler was programmed to promote a first denaturation at $94^{\circ} \mathrm{C}$ for $5 \mathrm{~min}$, and then 34 cycles of denaturation at $94^{\circ} \mathrm{C} / 30 \mathrm{~s}$, annealing at $65^{\circ} \mathrm{C} / 30 \mathrm{~s}$, and extension at $72^{\circ} \mathrm{C} / 45 \mathrm{~s}$ followed by a final extension at $72^{\circ} \mathrm{C} / 10 \mathrm{~min}$. The products were held at $4^{\circ} \mathrm{C}$. A $10 \mu$ l portion of the PCR products was analyzed by $4 \%$ polyacrylamide gel electrophoresis and stained with ethidium bromide. The gels were visualized and photographed on an ultraviolet transilluminator (Eagle eye II, Stratagene, CA, USA). The presence of the $123 \mathrm{bp}$ IS6110 product was considered a positive PCR result for MTBC.

Initial evaluation - During the first phase of our study, the sensitivity and specificity of the PCR primers were evaluated. Specificity was determined by testing DNA extracted from six mycobacterial 12B broth cultures: M. chelonae (ATCC 35752), M. kansasii (ATCC 12478), M. marinum (ATCC 927), M. tuberculosis H37Ra (ATCC 25177), M. africanum (ATCC 25420), and M. bovis (ATCC 35721). One E. coli (ATCC 29522) strain was also included as a negative control. To assess the sensitivity and competition at various levels of mycobacterial growth, DNA extracted from M. tuberculosis H37Ra 12B broth cultures presenting different GIs (66, $88,105,121$, and 552) were tested. All of these cultures were handled as previously described.

Cross-contamination - To minimize cross-contamination, aerosol resistant tips were used and changed for each sample. Separate rooms were used for (i) culture 
and sample preparation (heat killing and sedimentation), (ii) preparation of the master mix, and (iii) amplification and detection. To detect possible cross-contamination, negative controls were included in each batch.

\section{RESULTS}

The results of our preliminary study demonstrated that the primers used were specific for MTBC species (Fig. 2). None of the DNA isolated from the three mycobacteria other than MTBC were amplified. With respect to sensitivity, PCR was able to detect MTBC at all GIs tested, with no noticeable differences in the strength of the bands (Fig. 3).

A total of 107 BACTEC $^{\circledR}$ culture positive sputum specimens that attained a GI $\geq 30$ were assayed by PCR and subsequently tested by NAP at GI $\geq 50$. Of these, 90 were culture positive for MTBC (84.1\%), eight cultures (7.5\%) grew NTM, and 7 (6.5\%) were contaminated by microorganisms other than mycobacteria. These results are summarized in Table I. All of the 90 cultures positive for MTBC were PCR positive. Except for one, all cultures which grew NTM were PCR negative. The remaining seven cultures that did not grow any mycobacteria were PCR negative. In two cultures that grew both mycobacteria and other organisms than AFB, a phenotypic identification was not possible, and both of them were

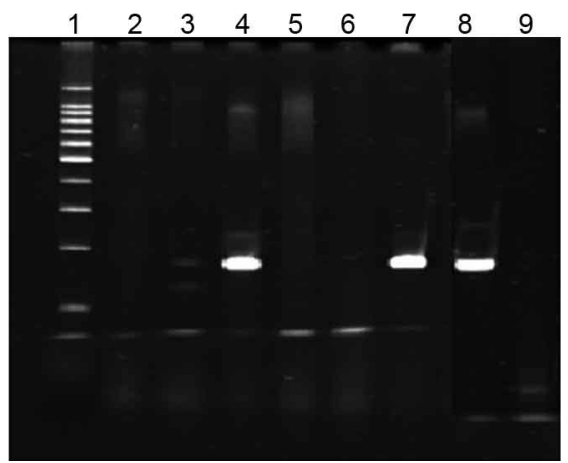

Fig. 2: detection of PCR products of IS6110 in direct BACTEC ${ }^{\circledR} 12 \mathrm{~B}$ cultures. Lanes - 1: 100 bp ladder marker; 2 : negative control (water); 3: M. marinum; 4: M. africanum ; 5: M. kansasii; 6: M. chelonae; 7: M. bovis; 8: M. tuberculosis H37Ra; 9: negative control (E. coli).

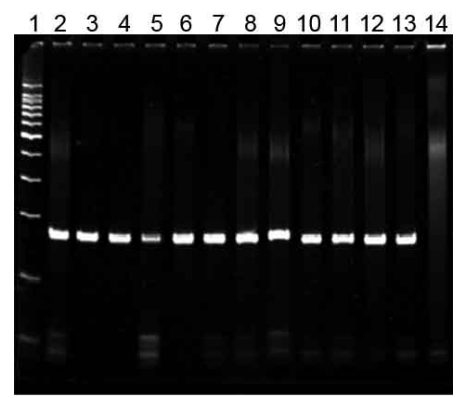

Fig. 3: results of the initial evaluation of PCR for the detection of $M$. tuberculosis H37Ra from 12B broth with different growth index (GI), pellet and supernatant, respectively. Lanes - 1: 100 bp ladder marker; $2,3: \mathrm{GI}=88 ; 4,5: \mathrm{GI}=66 ; 6,7: \mathrm{GI}=129 ; 8,9: \mathrm{GI}=552 ; 10,11: \mathrm{GI}=$ 105; 12, 13: GI $=121 ; 14$ : negative control (E. coli).
PCR negative. These samples were obtained from patients under treatment for $M$. tuberculosis infection. Of the 91 cultures which were PCR positive, 30.8\% (28/91) were assayed by PCR with GIs of $\leq 50$ while $35.2 \%$ $(32 / 91)$ were assayed with GIs between 51 and 100; the remaining vials were assayed with GIs of $>100$. In this study, three of the 90 cultures positive for MTBC were contaminated with other microorganisms, which was demonstrated by the $\mathrm{ZN}$ result and the subculture onto blood agar. PCR was able to further detect MTBC in these three mixed cultures, including one positive 12B vial that was ZN-negative for AFB (Table II).

To determinate the impact of PCR on decreasing the time to reporting of $M$. tuberculosis, we compared the time elapsed from specimen submission to identification of MTBC by the PCR and BACTEC ${ }^{\circledR}$ NAP methods. Although PCR can be performed in a few hours, it is more feasible to test all the positive 12B cultures detected in a day in one batch, which may mean performing PCR the following day. In BACTEC ${ }^{\circledR}$ broth inoculated with sputum samples, the average number of days required for identification of MTBC by PCR and NAP was 16.4 (10 to 27 ) and 26.1 (15.5 to 34), respectively (Table II). Of particular interest were the three contaminated $\mathrm{BACTEC}^{\circledR}$ $12 \mathrm{~B}$ broth cultures yielding MTBC growth with organisms other than AFB, which were successfully identified by PCR, resulting in a mean time to identify $M$. tuberculosis complex of 14 days before NAP identification.

\section{DISCUSSION}

Timely laboratory reporting of tuberculosis is important for prompt initiation of appropriate medical therapy for TB patients and rapid public health response (Drobniewski et al. 2003, Pascopella et al. 2004, WHO 2006). Molecular methods show promise for rapid and reliable detection of M. tuberculosis in sputum and other samples (Woods 2002, Ducati et al. 2006, Pinto et al. 2007).

Theoretically, the PCR method, in which nucleic acid is multiplied many times, could be more sensitive than the DNA probe method for identification of M. tuberculosis (Eisenach et al. 1990, Wolk et al. 2001). Data from several studies evaluating commercial PCR kits for direct detection of $M$. tuberculosis in clinical specimens have been extensively published, but studies that have investigated the ability of the assay to detect M. tuberculosis in broth culture systems have been rarely

TABLE I

Comparison of PCR results with that of final identification of Mycobacterium tuberculosis by culture

\begin{tabular}{lccc}
\hline & \multicolumn{3}{c}{ Phenotypic identification } \\
\cline { 2 - 4 } $\begin{array}{l}\text { PCR } \\
\text { result }\end{array}$ & M. tuberculosis & $\begin{array}{c}\text { Non-tuberculous } \\
\text { mycobacteria }\end{array}$ & $\begin{array}{c}\text { Other } \\
\text { microorganisms }\end{array}$ \\
\hline Positive & 90 & 1 & 0 \\
Negative & 0 & 7 & 7 \\
\hline Total $^{a}$ & 90 & 8 & 7 \\
\hline
\end{tabular}

$a$ : two mycobacterial cultures contaminated with other microorganisms which phenotypic identification was not possible were not included. 
TABLE II

Comparison of the median time to identify Mycobacterium tuberculosis by PCR and NAP methods

\begin{tabular}{lcccc}
\hline & \multicolumn{3}{c}{ Number of cultures positive for Mycobacterium tuberculosis } \\
\cline { 2 - 5 } AFB $^{a}$ smears and subculture results & \multicolumn{2}{c}{ PCR } & \multicolumn{2}{c}{ NAP $^{b}$} \\
\cline { 2 - 5 } from 12B broth with GI $\geq 30$ & Positive & Time (days) & Positive & Time (days) \\
\hline AFB positive & 87 & 11,6 & 86 & 15,5 \\
AFB positive + non-mycobacteria & 2 & 10 & $2^{c}$ & 25 \\
non-mycobacteria & 1 & 17 & 1 & 30 \\
AFB negative & 91 & 27 & 90 & 34 \\
\hline Total & 91 & - & -
\end{tabular}

$a$ : acid-fast bacilli; $b$ : $\rho$-nitro- $\alpha$-acetylamino- $\beta$-hydroxy-propiophenone test; $c$ : two mycobacterial cultures contaminated with other microorganisms which phenotypic identification was not possible were not included.

described (Cormican et al. 1992, Forbes \& Hicks 1994, Morris et al. 1994, Ryang et al. 1996, Muhumuza et al. 2006). In our study, we combined BACTEC ${ }^{\circledR}$ and PCR for rapid identification of the $\mathrm{MTBC}$ in cultures from respiratory specimens. The PCR assay used is based on the amplification of a fragment of $123 \mathrm{bp}$ in the IS6110. This sequence was chosen as a target in view of its high specificity and also because it provides a higher sensitivity due to its repetition along the chromosome (6-20 times in M. tuberculosis) (Thierry et al. 1990b, Flores et al. 2005, Negi et al. 2007). On the basis of our preliminary evaluations, the oligonucleotide primers derived from the IS6110 gene were successfully used to amplify a $123 \mathrm{bp}$ DNA sequence in mycobacteria belonging to the MTBC but not in other species. Although the protocol has a high stringency, two NTM samples presented a weak band (M. marinum and $M$. chelonae). Thus, to perform analysis of those bands, our preliminary study should use many NTM species and other species that may contaminate BACTEC vials. The primers used in our study also showed a high sensitivity, and the results obtained were similar to those reported by other authors who used amplification methods to detect the sequence IS6110 (Thierry et al. 1990a, Otal et al. 1997, Savelkoul et al. 2005). Our results also show that it was able to identify the presence of DNA MTBC at all GIs tested, ranging from 66 to 552 . Once the sensitivity and specificity of the primers were determined, we evaluated the ability of the PCR assay to identify MTBC from BACTEC ${ }^{\circledR}$ $12 \mathrm{~B}$ broth cultures. PCR was positive in all $90 \mathrm{MTBC}$ culture-positive samples. All NTM species were negative by PCR, except for one. These results confirm the value of in-house PCR in this role.

The time advantage that the radiometric method of detection and molecular technology for identification has given to the area of clinical mycobacteriology has been clearly documented (Bergmann \& Woods 1999, Desmond \& Loretz 2001). In this study, the time required to detect and identify mycobacteria in BACTEC ${ }^{\circledR} 12 \mathrm{~B}$ cultures by the PCR method was compared with that of identification by the NAP method. The median time savings for identification of mycobacteria with the PCR was about nine days compared to that of NAP identification. This observation is similar to those of earlier researchers (Forbes \& Hicks 1994, Ryang et al. 1996). In the report by Muhumuza et al. (2006), in-house PCR also identified MTBC six days earlier than the NAP results.

In addition to the long time necessary for $M$. tuberculosis growth, non-fastidious microorganisms eventually contaminate a small percentage of cultures. This may lead to errors in the diagnosis, and delays in the administration of appropriate treatment (Buijtels \& Petit 2005, Lima et al. 2005). In our study, PCR was able to provide the correct identification weeks earlier than when NAP test results became available. These results demonstrate that the presence of contaminating organisms did not interfere with MTBC detection in broth cultures by the PCR.

The phenotypic tests did not allow us to arrive at a definite diagnosis for two mixed-cultures presenting negative PCR. Unfortunately, the PCR results could not be confirmed because these samples had been discarded. Both of these samples were obtained from patients who had cultured positive for MTBC within the past five months, and all had been started on tuberculosis treatment. These possible false negative results could be explained by the presence of low numbers of organisms in the specimen or the inhibition of PCR by interfering substances in the sample, as reported by several investigators (Wolk et al. 2001). The elimination of inhibitory factors continues to be a challenge in the use and acceptance of PCR assays in a clinical diagnostic setting. The use of an internal control is of paramount importance, allowing for the evaluation of each individual reaction as to whether the reaction was inhibited by interfering substances (Wolk et al. 2001, Hoorfar et al. 2004).

Since mycobacterial DNA can be detected by amplification tests for a long time after the start of treatment and in the absence of positive cultures of tuberculosis (Yuen et al. 1993), the PCR positive results may not necessarily reflect an active disease by M. tuberculosis. Some studies have found PCR positive results from patients with only a tuberculosis infection or a past history of tuberculosis (Yuen et al. 1993, Rajalahti et al. 2001). In the present study, there was only one BACTEC ${ }^{\circledR}$ $12 \mathrm{~B}$ vial that was PCR positive for MTBC but culture positive for NTM. This specimen was obtained from one patient with a past history of treated tuberculosis. Although considered a false positive in our analysis, we feel that the PCR result cannot be totally ruled out as a possible true positive. 
To achieve better sensitivity than direct testing and better turnaround time than current culture and identification methods, mycobacteriology laboratories have been using commercially available nucleic acid amplification test kits to detect $M$. tuberculosis in BACTEC $^{\circledR} 12 \mathrm{~B}$ medium cultures (Desmond \& Loretz 2001). Despite considerable improvement of commercially available assays and their advantage in shortened turnaround times for diagnosis, these tests require a frequent supply of expensive commercial reagents or chips and are not expected to supplant culture for the definitive diagnosis of clinically significant mycobacterial infections (Bayram et al. 2006).

This study demonstrated a reliable and rapid assay that could be easily incorporated into a clinical laboratory routine. The conventional tests for detection of $M$. tuberculosis, culture, and microscopy are undoubtedly much cheaper than the PCR systems. However, none of these conventional methods combine a reasonable sensitivity with a reasonable test time, as in-house PCR does. Even though these methodologies might be expensive for developing countries, the cost-benefit of this test must be considered. It is less expensive than a prolonged patient stay in the hospital wards, which is common for tuberculosis patients; in many cases, these patients are waiting only for confirmation of the diagnosis. Based on the findings from our study, in-house PCR proved to be a useful and rapid means for the detection and identification of MTBC in 12B broth cultures. In addition, PCR has the potential to detect MTBC at an earlier phase of growth than those needed for the NAP method, even in the context of contaminated cultures.

\section{REFERENCES}

Bayram A, Celiksöz C, Karsligil T, Balci I 2006. Automatized PCR evaluation of Mycobacterium tuberculosis complex in respiratory and nonrespiratory specimens. FEMS Immunol Med Microbiol 46: $48-52$.

Bergmann JF, Woods GL 1999. Enhanced amplified Mycobacterium Tuberculosis Direct Test for detection of Mycobacterium tuberculosis complex in positive BACTEC 12B broth cultures of respiratory specimens. J Clin Microbiol 37: 2099-2011.

Buijtels PCAM, Petit PLC 2005. Comparison of $\mathrm{NaOH}-\mathrm{N}$-acetyl cysteine and sulfuric acid decontamination methods for recovery of mycobacteria from clinical specimens. J Microbiol Methods 62: 83-88.

Cleef MV, Kivihya-Ndugga L, Githui W, Ng'ang'a L, Kibuga D, Odhiambo J, Klatser P 2005. Cost-effectiveness of polymerase chain reaction versus Ziehl-Neelsen smear microscopy for diagnosis of tuberculosis in Kenya. Int J Tuberc Lung Dis 9: 877-883.

Collins CH, Grange JM, Yates MD 1997. Direct smears. In CH Collins, JM Grange, MD Yates, Tuberculosis bacteriology: organization and practice, Butterworth-Heinemann, Oxford, p. 48-56.

Cormican MG, Barry T, Gannon F, Flynn J 1992. Use of polymerase chain reaction for early identification of Mycobacterium tuberculosis in positive cultures. J Clin Pathol 45: 601-604.

CRPHF - Centro de Referência Professor Hélio Fraga 2002. Controle da tuberculose: uma proposta de integração ensino-serviço. Fundação Nacional de Saúde, Ministério da Saúde, Rio de Janeiro, 236 pp.

Cruciani M, Scarparo C, Malena M, Bosco O, Serpelloni G, Mengoli C 2004. Meta-analysis of BACTEC MGIT 960 and BACTEC 460 $\mathrm{TB}$, with or without solid media, for detection of mycobacteria. $J$ Clin Microbiol 42: 2321-2325.
Desmond EP, Loretz K 2001. Use of the Gen-Probe Amplified Mycobacterium Tuberculosis Direct Test for early detection of Mycobacterium tuberculosis in BACTEC 12B medium. J Clin Microbiol 39: 1993-1995.

Dowdy DW, Maters A, Parrish N, Beyrer C, Corman SE 2003. Costeffectiveness analysis of the Gen-Probe Amplified Mycobacterium Tuberculosis Direct Test as used routinely on smear-positive respiratory specimens. J Clin Microbiol 41: 948-953.

Drobniewski FA, Caws M, Gibson A, Young D 2003. Modern laboratory diagnosis of tuberculosis. Lancet 3: 141-147.

Ducati RG, Ruffino-Netto A, Basso LA, Santos DS 2006. The resumption of consumption. A review on tuberculosis. Mem Inst Oswaldo Cruz 101: 697-714.

Eisenach KD, Cave MD, Bates JH, Crawford JT 1990. Polymerase chain reaction amplification of a repetitive DNA sequence specific for Mycobacterium tuberculosis. J Infect Dis 161: 977-981.

Ellner PD, Kiehn TE, Cammarata R, Hosmer M 1988. Rapid detection and identification of pathogenic mycobacteria by combining radiometric and nucleic acid probe methods. J Clin Microbiol 26: 1349-1352.

Flores LL, Pai M, Colford Jr JM, Riley LW 2005. In-house nucleic acid amplification tests for the detection of Mycobacterium tuberculosis in sputum specimens: meta-analysis and meta-regression. $B M C$ Microbiol 3: 5-55.

Forbes BA, Hicks KE 1994. Ability of PCR assay to identify Mycobacterium tuberculosis in BACTEC 12B vials. J Clin Microbiol 32: $1725-1728$.

Giampaglia CMS, Martins MC, Chimara E, Oliveira RS, Vieira GBO, Marsico AG, Mello FC, Fonseca LS, Kritski A, Telles MAS 2007. Differentiation of Mycobacterium tuberculosis from other mycobacteria with rho-nitrobenzoic acid using MGIT960. Int J Tuberc Lung Dis 11: 803-807.

Giampaglia CMS, Martins MC, Inumaru VTG, Butuem IV, Telles MAS 2005. Evaluation of a rapid differentiation test for the $M y$ cobacterium tuberculosis complex by selective inhibition with $\rho$-nitrobenzoic acid and thiophene-2-carboxylic acid hydrazide. Int J Tuberc Lung Dis 9: 206-209.

Hoorfar J, Malorny B, Abdulmawjood A, Cook N, Wagner M, Fach P 2004. Practical considerations in design of internal amplification controls for diagnostic PCR assays. J Clin Microbiol 42: 1863-1868.

Kent PT, Kubica GP 1985. Public health mycobacteriology - a guide for level III laboratory, Department of Health and Human Services, Centers for Disease Control, Atlanta, USA, 280 pp.

Kivihya-Ndugga L, van Cleeff M, Juma E, Kimwomi J, Githui W, Oskam L, Schuitema A, van Soolingen D, Nganga L, Kibuga D, Odhiambo J, Klatser P 2004. Comparison of PCR with the routine procedure for diagnosis of tuberculosis in a population with high prevalences of tuberculosis and human immunodeficiency virus. J Clin Microbiol 42: 1012-1015.

Laszlo A, Siddiqi SH 1984. Evaluation of a rapid radiometric differentiation test for the Mycobacterium tuberculosis complex by selective inhibition with $\rho$-nitro- $\alpha$-acetylamino- $\beta$-hydroxypropiophenone. J Clin Microbiol 19: 694-698.

Lima DM, Bollela VR, Jácomo BJT, Martinez R, Fonseca BAL 2005. Identification of mycobacterium species in contaminated cultures by polymerase chain reaction. Chest 127: 1283-1288.

Morris A, Reller L, Devlin B 1994. Clinical usefulness of detecting growth of Mycobacterium tuberculosis in positive BACTEC phials using PCR. J Clin Pathol 47: 190-191.

Muhumuza J, Asiimwe BB, Kayes S, Mugyenyi P, Whalen C, Mugerwa RD, Boom H, Eisenach KD, Joloba ML 2006. Introduction of 
an in-house PCR for routine identification of $M$. tuberculosis in a low-income country. Int J Tuberc Lung Dis 10: 1262-1267.

Negi SS, Anand R, Pasha ST, Gupta S, Basir SF, Khare S, Lal S 2007. Diagnostic potential of IS6110, 38kDa, 65kDa and 85B sequencebased polymerase chain reaction in the diagnosis of Mycobacterium tuberculosis in clinical samples. Indian J Med Microbiol 25: 43-49.

Otal I, Samper S, Asensio MP, Vitoria MA, Rubio MC, Gómez-Lus R, Martín C 1997. Use of a PCR method based on IS6110 polymorphism for typing Mycobacterium tuberculosis strains from BACTEC cultures. J Clin Microbiol 35: 273-277.

Pascopella L, Kellam S, Ridderhorf J, Chin DP, Reingold A, Desmond E, Flood J, Royce S 2004. Laboratory reporting of tuberculosis test results and patient treatment initiation in California. $J$ Clin Microbiol 42: 4209-4213.

Piersimoni C, Scarparo C, Callegaro A, Tosi CP, Nista D, Bornigia S, Scagnelli M, Rigon A, Ruggiero G, Goglio A 2001. Comparison of MB/BacT ALERT 3D system with radiometric BACTEC system and Löwenstein-Jensen medium for recovery and identification of mycobacteria from clinical specimens: a multicenter study. J Clin Microbiol 39: 651-657.

Pinto H Jr, Bica CG, Palaci M, Dietze R, Basso LA, Santos DS 2007. Using polymerase chain reaction with primers based on the plcBplcC intergenic region to detect Mycobacterium tuberculosis in clinical samples. J Bras Pneumol 33: 437-442.

Rajalahti I, Vuorinen P, Liippo K, Nieminen MM, Miettinen A 2001. Evaluation of commercial DNA and rRNA amplification assays for assessment of treatment outcome in pulmonary tuberculosis patients. Eur J Clin Microbiol Infect Dis 20: 746-750.

Rishi S, Sinha P, Malhotra B, Pal N 2007. A comparative study for the detection of mycobacteria by BACTEC MGIT 960, Lowenstein Jensen media and direct AFB smear examination. Indian $J$ Med Microbiol 25: 383-386.

Rusch-Gerdes S, Richter E 2004. Clinical evaluation of the semiautomated BDProbe Tec ET System for the detection of Mycobacterium tuberculosis in respiratory and nonrespiratory specimens. Diagn Microbiol Infect Dis 48: 265-270.
Ryang DW, Ryang DH, Shin MG, Shin JH, Kee SJ, Suh SP 1996. Alternative use of polymerase chain reaction instead of rho-nitroalpha-acetylamino-beta-hydroxypropiophenone test for the early detection of Mycobacterium tuberculosis in BACTEC 12B cultures. APMIS 104: 444-450.

Savelkoul PHM, Catsburg A, Mulder S, Oostendorp L, Schirm J, Wilke H, van der Zanden AGM, Noordhoek GT 2005. Detection of Mycobacterium tuberculosis complex with Real Time PCR: comparison of different primer-probe sets based on the IS6110 element. J Microbiol Methods 66: 177-180.

Siddiqi SH 1989. BACTEC ${ }^{\circledR}$ TB System. Product and procedure manual. Becton Dickinson Diagnostic Instrument Systems. Maryland, USA, $27 \mathrm{pp}$.

Spada DTA, Santos MAA, Almeida EA, Augusto M, Albarral MIP, Melo FAF 2005. Evaluation of a genetic probe (Gen-Probe Accuprobe ${ }^{\circledR}$ system) in comparison to traditional methods for identifying members of the Mycobacterium tuberculosis complex. J Bras Pneumol 31: 219-224.

Thierry D, Brisson-Nöel A, Vincent-Lévy-Frébault V, Nguyen S, Guesdon J-L, Gicquel B 1990a. Characterization of a Mycobacterium tuberculosis insertion sequence, IS6110, and its application in diagnosis. J Clin Microbiol 28: 2668-2673.

Thierry D, Cave MD, Eisenach KD, Crawford JT, Bates JH, Gicquel B, Guesdon JL 1990b. IS6110, an IS-like element of Mycobacterium tuberculosis complex. Nucl Acids Res 18: 188.

WHO - World Health Organization 2006. The global plan to stop TB, 2006-2015. WHO/HTM/STB/2006.35.2006, Geneva, 172 pp.

Wolk D, Mitchell S, Patel R 2001. Principles of molecular microbiology testing methods. Inf Dis Clin North Am 15: 1157-1204.

Woods GL 2002. The mycobacteriology laboratory and new diagnostic techniques. Infec Dis Clin North Am 16: 127-144.

Yuen LKW, Ross BC, Jackson KM, Dwyer B 1993. Characterization of Mycobacterium tuberculosis strains from Vietnamese patients by southern blot hybridization. J Clin Microbiol 31: 1615-1618. 